\title{
Streaking Artifact
}

National Cancer Institute

\section{Source}

National Cancer Institute. Streaking Artifact. NCI Thesaurus. Code C87019.

An artifact resulting from an inconsistency in a single measurement. 